\title{
The Exploration of Academic English Vocabulary Teaching Model Based on POA
}

\author{
Weixuan $\mathrm{Shi}^{1}$, Wenqian $\mathrm{Li}^{{ }^{2}}$ \\ ${ }^{1}$ Professor in School of Foreign Languages, North China Electric Power University, NO 689 Road, North District, Baoding, Hebei, China \\ ${ }^{2}$ Graduate Student in School of Foreign Languages, North China Electric Power University, NO 689 Road, North District, Baoding, Hebei, China
}

DOI: $10.36348 /$ sijll.2021.v04i01.002 $\quad$ | Received: 22.12.2020 | Accepted: 08.01.2021 | Published: 11.01 .2021

*Corresponding author: Wenqian $\mathrm{Li}$

\section{Abstract}

At present, domestic vocabulary teaching, including academic English vocabulary teaching, mostly adopts traditional teaching methods. The current situation is that students with limited academic vocabulary have low academic competence. It is English teachers who have the duty and responsibility to help students expand their academic English vocabulary. Guided by the Production-oriented approach (POA), this article manages to construct the teaching design of academic English vocabulary teaching and explores effective ways to enhance students' academic English proficiency. This article finds that under the guidance of POA theory, academic English vocabulary teaching can more effectively stimulate students' internal motivation, promote the completion of production tasks, enhance students' sense of acquisition, and more accord with China's foreign language teaching practice.

Keywords: Production-oriented approach (POA), academic English, vocabulary teaching.

Copyright $\odot 2021$ The Author(s): This is an open-access article distributed under the terms of the Creative Commons Attribution 4.0 International License (CC BY-NC 4.0) which permits unrestricted use, distribution, and reproduction in any medium for non-commercial use provided the original author and source are credited.

\section{INTRODUCTION}

As the global economy develops rapidly, science and technology are progressing with each passing day. Diplomacy, trade, science and technology, culture, tourism, and communication in the world appear unprecedentedly frequent. English for Specific Purposes (ESP), unlike the well-known English for General Purposes (EGP), has received considerable attention by educators. Particularly academic English, as a kind of ESP, has an upward tendency driven by current situation. Academic English can be divided into English for General Academic Purposes (EGAP) and English for Specific Academic Purposes (ESAP). The former refers to the English language skills required to learn different subjects in an English academic environment, and the latter means the English language skills required to learn one specific subject.

Nation [1] believes that academic English vocabulary learning is vitally important and practical in that academic vocabulary appears frequently in various academic sectors; and among all vocabularies in academic literature, the number of academic vocabularies has an absolute advantage. Therefore, it is particularly important to learn and teach academic English vocabulary.
However, a large proportion of the domestic vocabulary teaching, including academic English vocabulary teaching, still adopts traditional teaching methods, while students are not equipped with enough academic vocabularies and academic competence. Hence, English teachers are responsible for helping students expand their academic English vocabulary.

Accordingly, this article explores effective ways to improve students' academic English, manages to construct a new teaching model of academic English vocabulary, and provides new approaches to ultimately improving students' academic ability and scientific research ability. In this way, not only can it meet the needs of the new era for innovative and internationally competitive talents, but also can better serve three key strategic goals, that is, the strategy of rejuvenating the country through science and technology, the strategy of strengthening the country through human resource development, and the strategy of innovation-driven development.

\section{LITERATURE REVIEW}

With regard to academic English vocabularies, foreign scholars have conducted multi-dimensional, systematic and in-depth researches including teaching strategies [2], the current situation and strategies of English vocabulary learning [3], the current situation of 
teaching and learning [4], testing methods [5], corpusbased teaching approach $[1,6]$ and so on. In particular, Coxhead [1] launched a new "Academic Word List" (AWL) with 570 word families on the ground of researches such as the General Word List (GSL). All of these existing fruits provide an important reference for domestic academic English vocabulary researches.

Production-oriented Approach (POA) is an English teaching theory with Chinese characteristics put forward by English teaching expert Qiufang Wen on the basis of Chinese students' situation. Its theoretical system principally consists of teaching philosophy, teaching hypothesis and teaching process with teachers as intermediary agents. POA has changed the conventional teaching sequence of "output after input", and has made up for the drawback of current vocabulary teaching by resolving the problem of "separation of learning and use".

For the past few years, scholars have carried out abundant teaching practices and discussions concerning POA in college English teaching. For example, POA is employed in teaching college English [7], in teaching English writing [8], in teaching oral English [9], etc. Despite several domestic studies applying POA for vocabulary teaching [10], they still focus on traditional classroom design and theoretical extension. Seldom do studies take advantage of POA in academic English vocabulary, and scholars merely attach importance to teaching process design and effectiveness at a certain stage of the POA teaching process. The good "components" of POA should be utilized in the teaching of academic English vocabulary to improve the effectiveness and innovation. It is theoretically feasible to enhance the teaching of academic English vocabulary from the perspective of POA, since academic English vocabulary teaching is a part of college English teaching.

This article attempts to introduce POA into academic English vocabulary teaching, hoping to explore the role of POA theory in academic English vocabulary teaching and make a detailed teaching design based on this.

\section{TEACHING DESIGN OF ACADEMIC ENGLISH VOCABULARY GUIDED BY POA}

According to Qiufang Wen [11], the academic English vocabulary teaching design under the guidance of POA is presented in the following table.

\begin{tabular}{|c|c|c|c|}
\hline Phase & \multicolumn{2}{|l|}{ Procedure } & Teaching content \\
\hline \multirow[t]{3}{*}{$\begin{array}{l}\text { Motivating } \\
\text { phase }\end{array}$} & \multicolumn{2}{|c|}{ Presentation of communication scene } & $\begin{array}{l}\text { A visiting professor from the United States is invited to } \\
\text { deliver academic lectures. As an assistant, you need to } \\
\text { understand his English academic paper and present the main } \\
\text { contents to the audience }\end{array}$ \\
\hline & \multicolumn{2}{|c|}{ Production task attempt } & $\begin{array}{l}\text { Students are aware of the lack of academic vocabularies, } \\
\text { which results in a "sense of hunger" and a strong desire for } \\
\text { students to learn. }\end{array}$ \\
\hline & \multicolumn{2}{|c|}{$\begin{array}{l}\text { Teaching goals/ production task } \\
\text { description }\end{array}$} & $\begin{array}{l}\text { Communicative goal: to understand and summarize the main } \\
\text { contents and ideas of the academic paper, and to produce an } \\
\text { introduction of the professor's paper using academic } \\
\text { vocabulary } \\
\text { Linguistic goal: to master the academic words, phrases and } \\
\text { collocations needed to achieve the communicative goal }\end{array}$ \\
\hline \multirow[t]{6}{*}{$\begin{array}{l}\text { Enabling } \\
\text { phase }\end{array}$} & \multirow[t]{2}{*}{ Content } & Target content & $\begin{array}{l}\text { The whole contents and viewpoints of an English academic } \\
\text { paper }\end{array}$ \\
\hline & & Enabling mode & Material reading, topic discussion and information summary \\
\hline & \multirow[t]{2}{*}{ Linguistic form } & Target language & Key academic vocabulary and phrases in materials \\
\hline & & Enabling mode & Text reading, teacher's explanation, and language practice \\
\hline & \multirow{2}{*}{$\begin{array}{l}\text { Discourse } \\
\text { structure }\end{array}$} & Target structure & Questions posing - questions explaining - questions solving \\
\hline & & Enabling mode & $\begin{array}{l}\text { Examples demonstration, structure extraction and imitation } \\
\text { learning }\end{array}$ \\
\hline \multirow[t]{3}{*}{$\begin{array}{l}\text { Assessing } \\
\text { phase }\end{array}$} & \multirow{3}{*}{$\begin{array}{l}\text { Teacher-Student } \\
\text { Collaborative } \\
\text { Assessment }\end{array}$} & Pre-class & $\begin{array}{l}\text { Teachers: choosing the focus of evaluation and reviewing } \\
\text { the typical sample essays }\end{array}$ \\
\hline & & In-class & $\begin{array}{l}\text { Students' independent thinking - group discussion - teacher- } \\
\text { guided class communication - teacher participation } \\
\text { evaluation }\end{array}$ \\
\hline & & Post-class & Students' self-evaluation and group mutual evaluation \\
\hline
\end{tabular}

\section{Motivating Phase}

In this teaching design, discussing the main content of English academic papers can help students deepen their awareness of their own knowledge, discover their inadequacy of academic English vocabulary in time, and pay attention to autonomous learning and vocabulary accumulation after class. Therefore, the motivating phase exerts an important 
role in helping them integrate their knowledge structure, master academic English vocabulary, and improve their academic language skills.

The main task of the motivating phase is to make students realize their own shortcomings by urging students to produce tasks, thereby arousing their enthusiasm and desire for learning. This phase includes three steps:

1. The teacher presents a communication scene. To satisfy students' needs of academic vocabulary, the communication scene designed in this article is as follows. Supposing a visiting professor from the United States is invited to deliver academic lectures, you, as an assistant, need to understand his English academic paper and present the main contents and opinions in advance to the audience who participate in the lecture.

2. Students attempt to produce the task. According to the above scene, students try to finish the task in the first place. But due to the insufficient accumulation of academic English vocabulary, students will realize personally the difficulty of reading English academic papers, as it is not easy to completely grasp the content. Pressure and motivation are naturally generated in their hearts, and they are in the "starvation state" of academic vocabulary.

3. The teacher describes the teaching goals and production tasks. Teaching goals are divided into the communicative goal and linguistic goal: the former means that students should be able to understand and summarize the main contents and ideas of the academic paper, and to use academic vocabulary for oral and written expression; the latter means that students must master the academic words, phrases, and collocations in the paper.

Production tasks are classified into two types: in-class and extra-curricular task. In-class task refers to the production exercises that are carried out simultaneously with input learning; extra-curricular task refers to the production exercises that teachers require students to finish after class, which includes review and transfer task [11]. The review task is to ask students to look up unfamiliar academic vocabulary and phrases in the paper, and mark the difficulties to understand in the content. The transfer task is to require students in small groups to collect relevant domestic and foreign literature. These two extra-curricular tasks must be uploaded to the class WeChat group within the prescribed time limit for everyone to read and communicate with each other for later assessment.

\section{Enabling Stage}

Input-enabled hypothesis requires teachers to lay stress on instructing students to produce appropriate input materials in the classroom. In the academic English vocabulary classroom, the teacher's input materials have an important influence on students' vocabulary learning after class. It is inevitable that academic vocabularies include a lot of new vocabularies and the correlation between different academic vocabularies is unpredictable, which is difficult for students to remember and learn. In order to carry out academic English vocabulary teaching, teachers need to select appropriate input materials to inspire students, provide help for establishing a structure for learning new knowledge, and promote students to master and use academic English vocabulary.

The main task of the enabling phase is to help students "cut paths through the mountains and build bridges across the rivers", and provide scaffolding for students to complete output tasks [12]. This is the most critical and challenging stage in POA and can be refined into the following steps:

1. The teacher describes the production task. In order to reduce the difficulty and distance between output and input learning, the production task can be broken down into four subtasks: one is to learn the academic English vocabulary and usage in the paper; the second is to understand all the content in the paper; the third is to summarize the author's research content, research goals, research process and research results; the fourth is to use academic English vocabulary to make an introduction of the professor's academic paper.

2. Students set about selective learning, and the teacher gives guidance and inspection. In response to the above tasks, students are provided with input materials, which mainly include professional terminology in relevant fields of the paper, basic knowledge of pertinent theories, characteristics of academic English vocabulary, and advanced academic vocabulary commonly used in English papers. According to the principle of selective learning, the teacher has different emphasis on each part of the teaching. Firstly, the teacher should guide students to focus on the ideas and content in the paper; secondly, the teacher should guide students to focus on the academic vocabulary in the paper; thirdly, the teacher should guide students to learn to apply academic English vocabulary to writing. In the process of guidance, the teacher should give timely inspection and guidance to students' stage performance.

3. Students practice the production, and the teacher gives guidance and inspection. Production tasks can include academic vocabulary dictation, imitative writing sentences, text structure induction, etc. All production exercises must be carried out step by step under the guidance of the teacher, from the easy one to the difficult one, and be assessed immediately after completion of practicing. 


\section{Assessing Phase}

The POA starts with production and ends with production, putting a premium on the effective assessment of students' language production [14]. This teaching design mainly uses Teacher-Student Collaborative Assessment (TSCA) to evaluate the submitted introduction of the professor's paper with academic vocabulary students have learned in class. This teaching design changes the previous model of a single evaluation of students by teachers, adopting multi-dimensional evaluation subjects to stimulate students' enthusiasm for learning English academic vocabulary. The detailed steps are as follows:

1. Pre-class stage. After students compose English writing with the academic vocabulary learned in class, teacher needs to determine the focus of evaluation in advance and conduct selective assessment [13]. First, teacher can focus on the vocabulary problems in most student articles, such as academic vocabulary usage or collocation problems, select typical samples, and review them in detail. At the same time, according to the key and difficult points of vocabulary learning, appropriate vocabulary exercises can be compiled to help students solve common problems in the process of learning academic vocabulary [14].

2. In-class stage. This stage is the most critical. The teacher first explains the assessing goals, requirements, and steps to the students, then asks the students to make independent evaluations on the vocabulary problems that appear in the typical samples. Then after group discussions, the whole class discusses how to use academic vocabularies under the leadership of the teacher. Finally, the teacher gives the review and revision comments prepared before the class, allowing students to discuss and compare their evaluation with the teacher's. In addition, as for the common problems of academic vocabulary in writing, the teacher guides students to complete the exercises prepared in advance to consolidate and strengthen academic English vocabulary.

3. Post-class stage. Students will conduct selfevaluation or peer-evaluation on the submitted work according to the suggestions on revision discussed in class. In this process, students can consolidate and internalize the academic English vocabulary they have learned, thereby realizing the "promoting learning" function of assessment. For students' corrections, the teacher will carry out general or partial random checks to know students' self-evaluation or mutual evaluation and the state of students' vocabulary learning as well. The teacher can communicate and summarize through the class WeChat group, and upload 2 to 3 excellent works for students to learn from and help students to remember more words.
ADVANTAGES OF ACADEMIC ENGLISH VOCABULARY TEACHING DESIGN BASED ON POA

The output-driven POA can more effectively stimulate the inner motivation of students.

For many Chinese students, they have less access to academic English in their daily life. It is a priority to cultivate their desire to use academic English for communication in order to truly improve their accumulation of academic English vocabulary and academic English knowledge so that they can handle very skillfully in future academic English learning and communication.

Compared with the traditional "text-centered" teaching model, in the motivating phase of POA, after the teacher presents the communication scene, the teacher immediately asks the students to try to produce academic vocabulary, so that students can experience the demand for academic English vocabulary in real life and then have a strong willingness to communicate. By devising production tasks with "potential communicative value", POA allows students to realize their lack of academic English and actively learn academic English vocabulary.

\section{Teacher-directed POA can more effectively promote the completion of production tasks}

POA advocates that the teacher should play the role of "scaffolding" in every aspect of the teaching process [15]. Without adequate training on academic English ability of Chinese students, they shy away from academic English in fear of difficulty. When designing tasks, the teacher should ensure that the input tasks and the output tasks are highly compatible, and the difficulty of the task should correspond to students' current academic vocabulary level to reduce students' frustration. At the same time, the teacher should give students assistance and guidance from all aspects for each subtask.

Therefore, the teaching under the guidance of POA is more suitable for the current situation of poor academic English of college students, and can ensure that students master some academic English vocabularies in the limited classroom time, thereby promoting the completion of production tasks.

\section{POA assessment can effectively increase students' sense of fulfillment}

Assessment occupies an important position in the POA system. POA emphasizes that every production task of students must be effectively assessed. Under the guidance of teachers, students can evaluate their performance and learn more in the process of in-class learning. Through various evaluation methods such as teacher evaluation, teacher-student collaborative assessment, student self-evaluation, and peer evaluation, each production task of students can be 
evaluated in a timely, effective, and comprehensive way.

Through a variety of in-class and extracurricular evaluation methods, students can timely realize their performance after fulfilling each task in the academic vocabulary learning process, clearly know their progress at each stage. Hence, it is easy for them to gain a sense of accomplishment, and their motivation for learning academic English vocabulary can be stimulated as well.

\section{CONCLUSION}

This article is an attempt to apply POA to the teaching model of academic English vocabulary. Dingfang Shu [16] has repeatedly called for the establishment of a "foreign language teaching theory with Chinese characteristics". From the perspectives of ontology, practice and methodology, Chinese scholars are advised to carry out in-depth and meticulous investigation and research on China's national conditions and academic conditions, and form a set of English teaching theoretical systems that are in line with China's reality. POA is an innovative foreign language teaching theory proposed in accordance with our foreign language teaching practice. It is true that, like all emerging theories, POA still needs to be further tested and developed in practice. The teaching design based on POA in this article requires the vast number of frontline teachers to boldly explore its effects and advantages in teaching practice, and to continuously revise and improve it.

\section{ACKNOWLEDGEMENTS}

This research is financially supported by "Research and practice of English teaching reform in Hebei province" (Grant No. 2020YYJG077).

\section{REFERENCES}

1. Coxhead, A., \& Nation, P. (2000). Research Perspectives on English for Academic Purposes: The specialised vocabulary of English for academic purposes. Cambridge: Cambridge University Press.

2. Brick, J., Herke, M., \& Wong, D. (2020). Academic Culture: A student's guide to studying at university 4 th edn.

3. Mardali, J., \& Siyyari, M. (2019). English teachers' beliefs and practices in teaching vocabulary: The case of teaching experience. Cogent Education, 6(1).

4. Green, C. (2019). The Mid-level Constructions of Academic Vocabulary: Towards a Pedagogical
Resource. British Association of Applied Linguistics, BAAL 2019, Manchester, August 2831 .

5. Laufer, B., Elder, C., Hill, K., \& Congdon, P. (2004). Size and strength: do we need both to measure vocabulary knowledge?. Language testing, 21(2), 202-226.

6. Celik, S., \& Keser, H. (2010). The Effect of DataDriven Learning Approach on EFL Learners' Lexical Acquisition. TIM VE BILIM, 35(158):184-198.

7. Lingli, Z. (2017). Research on the teaching effectiveness of "Production-oriented Approach". Modern Foreign Languages, (3), 369-376+438.

8. Yi, Z., \& Lijun, T. (2018). Analysis of the Change Path of English Writing Ability Based on the "Production-Oriented Teaching Method". Chinese Journal of Education, (S1), 137-139.

9. Hanchun, Z. (2019). A follow-up study on the impact of "Production-oriented Approach" on non-English major college students' oral anxiety. Foreign Languages and Translation, (03), 81-86.

10. Yan, Z. (2019). Application analysis of POA in college English vocabulary teaching. Education Teaching Forum, (19), 92-93.

11. Qiufang, W. (2015). Constructing the theoretical system of "Production-oriented approach". Foreign Language Teaching and Research, (4):547-558.

12. Yong, Z., \& Xue, B. (2019). The application of "production-oriented approach" in teaching Chinese as a foreign language: an investigation of the achievement of output goals. Teaching Chinese in the World, (1): 95-103.

13. Shuguang, S. (2017). "Teacher-student cooperation evaluation" classroom reflective practice research. Modern Foreign Languages, (3): 397-406.

14. Qiufang, W. (2016). “Teacher-student cooperation evaluation": a new evaluation form created by the "Production-oriented Approach". Foreign language circles, (5): 37-43.

15. Qiaozhen, C. (2017). An analysis of the role of teacher mediation in the "Production-oriented Approach"-Taking the fourth unit of the second volume of "New Generation College English" as an example. Foreign Language Education in China, (1): 15-22.

16. Dingfang, S. (2017). The deep practical foundation of foreign language teaching theory with Chinese characteristics-Mr. Lu Gusun's foreign language teaching ideas and propositions. Foreign Language Circle. (1): 15-21. 